\title{
Metrics of progress in the understanding and management of threats to Australian
}

\section{birds}

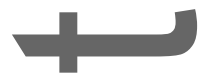

Garnett ST ${ }^{1}$, Butchart $\mathrm{SHM}^{2,3}$, Baker $\mathrm{GB}^{4}$, Bayraktarov E ${ }^{5}$, Buchanan $\mathrm{KL}^{6}$, Burbidge $\mathrm{AA}^{7}$, Chauvenet $\mathrm{ALM}^{8}$, Christidis L ${ }^{9}$, Ehmke $\mathrm{G}^{5,10}$, Grace $\mathrm{M}^{11}$, Hoccom DG ${ }^{12}$, Legge SM ${ }^{5,13}$, Leiper $\mathrm{I}^{1}$, Lindenmayer $\mathrm{DB}^{13}$, Loyn $\mathrm{RH}^{14,15,16}$, Maron $\mathrm{M}^{5,17}$, McDonald $\mathrm{P}^{18}$, Menkhorst $\mathrm{P}^{19}$, Possingham $\mathrm{HP}^{5,20}$, Radford $\mathrm{J}^{21,22}$, Reside $\mathrm{AE}^{5}$, Watson $\mathrm{DM}^{15}$, Watson $\mathrm{JEM}^{5,17,23}$, Wintle $\mathrm{B}^{24}$, Woinarski $\mathrm{JCZ}^{1}$ and Geyle $\mathrm{HM}^{1 *}$.

1. Threatened Species Recovery Hub, National Environmental Science Program, Research Institute for the Environment and Livelihoods, Charles Darwin University,

Northern Territory 0909, Australia

2. BirdLife International, David Attenborough Building, Pembroke Street Cambridge CB2 3QZ,U.K.

3. Department of Zoology, The University of Cambridge, Downing Street, Cambridge CB2 3EJ U.K.

4. Institute for Marine and Antarctic Studies, The University of Tasmania, Hobart, Tasmania 7005, Australia

5. Threatened Species Recovery Hub, National Environmental Science Program, Centre for-Biodiversity and Conservation Science, The University of Queensland, St Lucia,

Queensland 4072, Australia

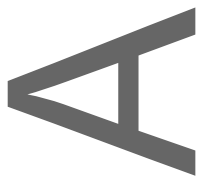

This is the author manuscript accepted for publication and has undergone full peer review but has not been through the copyediting, typesetting, pagination and proofreading process, which may lead to differences between this version and the Version of Record. Please cite this article as doi: $\underline{10.1111 / \text { cobi.13220. }}$.

This article is protected by copyright. All rights reserved. 
6. School of Life and Environmental Sciences, Deakin University, 75 Pigdons Rd, Geelong, Victoria 3216, Australia

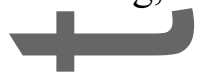

7. 87 Rosedale St, Floreat, Western Australia 6014, Australia

8. School of Environment and Science \& Environmental Futures Research Institute,<smiles>[CH]1[CH]C[CH]1</smiles>

Griffith University, Gold Coast, Queensland 4222, Australia

9. National Marine Science Centre, Southern Cross University, Lismore, New South

Wales 2480, Australia

10. BirdLife Australia, Carlton, Victoria 3053, Australia

11. Department of Zoology, The University of Oxford, Oxford OX1 3PS, U.K.

12. Royal Society for the Protection of Birds, Bedfordshire SG 19 2DL, U.K.

13. Threatened Species Recovery Hub, National Environmental Science Program, Fenner Sehool of Environment and Society, The Australian National University, Canberra,

Australian Capital Territory 2601, Australia

14. The Centre for Freshwater Ecosystems, School of Life Sciences, La Trobe University, Wodonga, Victoria 3690, Australia

15.Institute for Land, Water and Society, Charles Sturt University, Albury, New South Wales 2640, Australia

16. Eco Insights, Beechworth, Victoria 3747, Australia

17. School of Earth and Environmental Sciences, The University of Queensland, St Lucia 4072, Australia 
18. Zoology, School of Environmental and Rural Science, University of New England, Armidale, New South Wales 2351, Australia

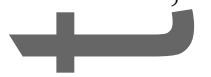

19. Arthur Rylah Institute for Environmental Research, Department of Environment, Land, Water and Planning, Heidelberg, Victoria 3084, Australia

(

20. The Nature Conservancy, Arlington, Virginia 22203-1606, U.S.A.

21. Department of Ecology, Environment and Evolution, La Trobe University, Bundoora, Victoria 3086, Australia

22. Research Centre for Future Landscapes, La Trobe University, Bundoora, Victoria 3086, Australia

23. Wildlife Conservation Society, Bronx, New York 10460-1068, U.S.A.

24. School of Bioscience, The University of Melbourne, Parkville, Victoria 3010,
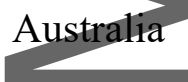

*Address correspondence to H.M. Geyle, email hayley.geyle@cdu.edu.au



Running head: Metrics of progress

Keywords: conservation performance, threat reduction, avian, threatened species, recovery planning

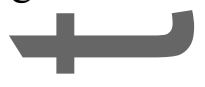

\section{Article Impact Statement}

Quantification of heeds and achievements in research and management will help conservation funders and practitioners prioritize investment and action. 


\section{Abstract}

Although evidence-based approaches have become commonplace for determining the success of conservation measures for the management of threatened taxa, there are no standard metrics for assessing progress in research or management. We developed 5 metrics to meet this need for threatened taxa and to quantify the need for further action and effective alleviation of the threats. These metrics (research need, research achievement, management need, management achievement, and percent threat reduction) can be aggregated to examine trends for an individual taxon or for threats across multiple taxa. We tested the utility of these metrics by applying them to Australian threatened birds, which appears to be the first time that progress in research and management of threats has been assessed for all threatened taxa in a faunal group at a continental scale. Some research has been conducted on nearly threequarters of known threats to taxa, and there is a clear understanding of how to alleviate nearly half of the threats with the highest impact. Some management has been attempted on nearly half the threats. Management outcomes ranged from successful trials to complete mitigation of the threat, including for one-third of high-impact threats. Progress in both research and management tended to be greater for taxa that were monitored, occurred on oceanic islands, or had recovery plans. Predation by cats had the highest potential threat score. However, there has been some success reducing the impact of cat predation, so climate change (particularly drought), now poses the greatest threat to Australian threatened birds. Our results demonstrate the potential for the proposed metrics to encapsulate the major trends in research and management of both threats and threatened taxa and provide a basis for international comparisons of evidence-based conservation science. 


\section{Introduction}

Robust, unbiased, transparent, and broadly applicable measures of how much has been achieved in conservation and how much is still needed are key to ensuring ongoing support (Sutherland et al.2004), efficient resource allocation and development of sound policy (Ferraro \& Pattanayak 2006). Existing metrics, such as the Red List Index (Butchart et al. 2005, 2007) or the U.S. Fish and Wildlife Service's (1983) favorability scores, are insufficiently sensitive to understand the effectiveness of management or to compare management effectiveness across threats and taxa. Assessments of success and impact for species recovery projects (Kapos et al. 2008) are not standardized and, as such, not suitable for comparison of large numbers of taxa.

General measures of conservation progress are made available through the conservation action planning process (Schwartz et al. 2012). However, the Royal Society for the Protection of Birds (RSPB) seems to be the only organization to have developed a set of defined categories for assessing progress toward an explicit final conservation target (RSPB 2017). Under their system, the lowest level of progress is associated with taxa with no monitoring, research, or management, and the highest level applies when population or range targets have been met and the conservation status of the species has been secured. These categories allow ready comparison of progress toward whatever targets are deemed appropriate for a taxon and can be translated into a traffic light system for visualisation and interpretation.

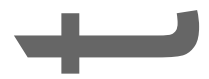

However, the process by which the RSPB applies aggregated information to assign the category of progress for each species is not widely known. Given that the key to progress in the conservation of threatened taxa is threat reduction (Meredith et al. 2018), measuring progress in alleviating each threat (Salafsky \& Margoulis 1999) can illuminate the components of such progress. 
Threat management has 2 phases: research and implementation. The research phase (equivalent to the diagnosis phase of Westwood et al. [2014]) aims to understand the nature of a threat (i.e., how it is affecting a taxon and the actions required to alleviate it). This phase commonly has few direct benefits in terms of threat reduction or population increase. Implementation involves managers applying research findings and ends when a taxon can maintain a self-sustaining population (Redford et al. 2011; Westwood et al. 2014; RSPB 2017). There is a need for metrics that will allow measurement of progress in alleviating threats across multiple taxa and to facilitate their management. Alleviation of high-impact threats benefit taxamore than will easing of threats with low or negligible impacts, particularly if existing management is negligible. Combining these ideas into standardized metrics allows retrospective assessment of how effective past interventions have been and can help direct resources to the most pressing targets across demands for research and management. We applied standardized metrics to threatened Australian bird taxa to quantify the effectiveness of threat alleviation and provide the means to allocate resources in a manner that maximizes the benefits of threat reduction to threatened taxa.

\section{Methods}

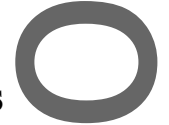

Our approach to assessing and understanding progress in threat alleviation among Australian threatened birds had 5 components: identifying threats affecting different taxa; assessing the timing, scope, and severity of those threats to create weighted threat impact scores that were then assigned to weighted categories; assessing the level of understanding about how to manage each threat; determining success in managing the threat; and assembling threat impacts, understanding, and management success into metrics of progress for an individual 
taxon or threat. To illustrate application of the metrics, we compared them with characteristics of the taxa or the threats.

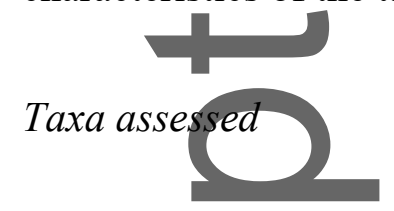

To demonstrate our method, we assessed 238 Australian bird taxa (species and subspecies). This included all those listed as threatened or near threatened at any time in the last 25 years (Garnett et al. 2015) or taxa currently listed under Australia's Environment Protection and Biodiversity Conservation Act 1999 (EPBC Act; Department of the Environment and Energy 2017). Taxonomy followed Garnett et al. (2015). We updated passerine taxonomy to account for taxonomic revisions published in del Hoyo and Collar (2016).

Threats

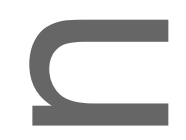

All threats $(t)$ known to have affected the selected taxa $(x)$ were first identified from Garnett et al. (2011) because these threat assessments have undergone multiple iterations over the last 20 years. Threat assessments were then updated and validated by experts. Multiple viewpoints were elicited wherever possible (see Supporting Information). Threats were then categorized using the IUCN Red List threat classification scheme (IUCN 2012) down to the most specific level possible. Extra detail was provided where available on invasive species, fishing type, mining target, recreational activity and climate impact. Then, following IUCN (2012), we assessed the timing of each threat (i.e., ongoing, may occur or return in the short rasse term, may occur or return in the distant future); its extent or scope (i.e. the proportion of the total population affected); and its severity (i.e., the rate of population decline caused by the threat within its scope), each with reference to Garnett et al. (2011) before review and validation by 1 or more experts on the taxon. To measure progress in alleviating threats, we estimated the timing, scope, and severity of threats for the existing impact, which accounts 
for any management and for the potential threat impact under the counterfactual assumption that no management of the threat had been undertaken (Ferraro \& Pattanayak 2006; Ferraro 2009) since 1900

The timing, scope, and severity of each threat were translated into a weighted impact score $\left(I_{t}\right)$ for both the actual situation $\left(I_{t a}\right)$ and the counterfactual scenario $\left(I_{t c}\right)$. Impact scores reflect the total population decline over ten years or three generations (whichever longer) likely to be caused by that threat (i.e. the product of scope and severity), weighted by threat timing (IUCN 2012) (see Supporting Information for greater detail). Where no action had been undertaken, $I_{t a}=I_{c c}$.

\section{Progress in understanding threats or implementing management}

The extent of progress in alleviating each threat to each taxon was divided into 2 parts: management understanding (MU), which represented the current level of knowledge of how to manage threat $t$ for taxon $x$, and management implementation (MI), which represents the extent to which threat $t$ has been alleviated for taxon $x$. For MU there were seven mutually exclusive categories ranging from no knowledge and no research to research complete and being applied or ongoing research associated with adaptive management of threat (Table 1). For MI there were another seven mutually exclusive categories ranging from no management to threat no longer needs management. Each step was scored from 0 to 6 for both MU and MI. Both metrics were derived from RSPB categories of progress in species conservation (RSPB 2017) (see Supporting Information for categories and data) but, unlike that framework, research and management were separated. We did not assume initiation of management action for a threat was contingent on complete knowledge of how to undertake management. 
Weighted data were assembled into 5 metrics applied both to individual taxa and to specific threats: 2 for progress in understanding (research need and research achievement), 2 for progress in management (management need and management achievement), and 1 for assessing overall progress in threat reduction (percent threat reduction). These metrics help highlight gaps in understanding and management and identify achievements.

Basic Metrics

For each threat $(t)$ faced by each taxon $(x)$, we calculated research need $(\mathrm{RN})$ and management need $(\mathrm{MN})$ such that

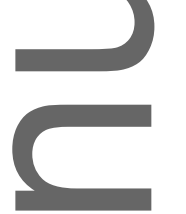

$$
\mathrm{RN}_{x t}=I_{x t c} \times\left(1-\frac{\mathrm{MU}_{x t}}{\mathrm{MU}_{(\max )}}\right)(1)
$$

and
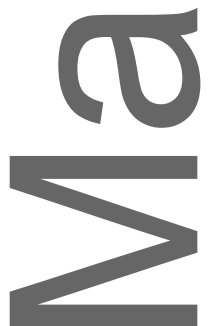

$$
\mathrm{MN}_{x t}=I_{x t c} \times\left(1-\frac{\mathrm{MI}_{x t}}{\mathrm{MI}_{(\max )}}\right),(2)
$$

where $\mathrm{MU}_{x t}$ and $\mathrm{MI}_{x t}$ are management understanding and implementation respectively, $\mathrm{MU}_{(\max )}$ and $\mathrm{MI}_{(\max )}$ are both 6 , and $I_{x t c}$ is threat impact under the assumption there has been no management.

We also calculated research achievement (RA) and management achievement (MA) such that

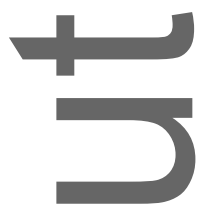

$$
\mathrm{RA}_{x t}=\frac{I_{x t c} \times \mathrm{MU}_{x t}}{\mathrm{MU}_{(\max )}}
$$

and



$$
\mathrm{MA}_{x t}=\frac{I_{x t c} \times \mathrm{MI}_{x t}}{\mathrm{MI}_{(\max )}}
$$




\section{Taxon Scores}

Where multiple threats affect a taxon, effects can be additive, antagonistic (one threatening process inhibits another) or synergistic (impact is magnified [Côté et al. 2016]). As there is no universal rule on how threat impacts combine, we calculated overall research needs or achievements in managing all known threats to a taxon by summing the taxon-specific research needs or achievements for a given threat and then dividing by the maximum possible score for each threat to provide a measure that can be compared among threats. Hence, the research need $\left(\mathrm{RN}_{x}\right)$ and management need $\left(\mathrm{MN}_{x}\right)$ for a given taxon $(x)$ are

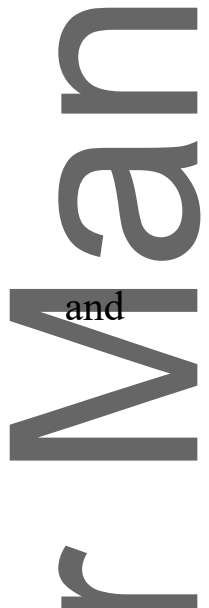

$$
\begin{gathered}
\mathrm{RN}_{x}=\frac{\sum_{t=1}^{j} \mathrm{RN}_{x t}}{I_{t(\text { max })} \times \mathrm{MU}_{(\max )} \times t_{j(\max )}},(5) \\
\mathrm{MN}_{x}=\frac{\sum_{t=1}^{j} \mathrm{MN}_{x t}}{I_{t(\max )} \times \mathrm{MI}_{(\max )} \times t_{j(\max )}},
\end{gathered}
$$

where $j$ is the number of threats facing a taxon, $I_{t(\max )}$ is the maximum weighting for threat impact (i.e. 63.0) (Table 2), and $t_{j(\max )}$ is the number of IUCN threat types coded to the lowest (i.e., most specific) level operating on any taxon which, for Australian threatened birds, is 25 (the number of threats affecting the Orange-bellied Parrot [Neophema chrysogaster]).

The research achievement $\left(\mathrm{RA}_{x}\right)$ and management achievement $\left(\mathrm{MA}_{x}\right)$ for a given taxon across all threats are similarly

$$
\mathrm{RA}_{x}=\frac{\sum_{t=1}^{j} \mathrm{RA}_{x t}}{I_{t(\max )} \times \mathrm{MU}_{(\max )} \times t_{j(\max )}}(7)
$$


and

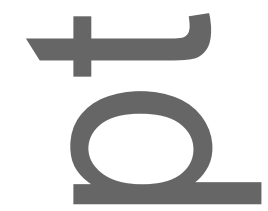

$$
\mathrm{MA}_{x}=\frac{\sum_{t=1}^{j} \mathrm{MA}_{x t}}{I_{t(\max )} \times \mathrm{MI}_{(\max )} \times t_{j(\max )}}
$$

\section{Threat Scores}

We calculated overall research needs or achievements in managing threats to Australian birds by summing the basic metrics $\mathrm{RN}_{x t}, \mathrm{MN}_{x t}, \mathrm{RA}_{x t}$ or $\mathrm{MA}_{x t}$ then dividing them by the total threat score for all threatened Australian bird taxa such that



$$
\begin{aligned}
\mathrm{RN}_{t} & =\frac{\sum_{x=1}^{j} \mathrm{RN}_{x t}}{\sum_{t=1}^{j} \sum_{x=1}^{k} \mathrm{RN}_{x t}},(9) \\
\mathrm{MN}_{t} & =\frac{\sum_{x=1}^{j} \mathrm{MN}_{x t}}{\sum_{t=1}^{j} \sum_{x=1}^{k} \mathrm{MN}_{x t}},(10) \\
\mathrm{RA}_{t} & =\frac{\sum_{x=1}^{j} \mathrm{RA}_{x t}}{\sum_{t=1}^{j} \sum_{x=1}^{k} \mathrm{RA}_{x t}},(11)
\end{aligned}
$$

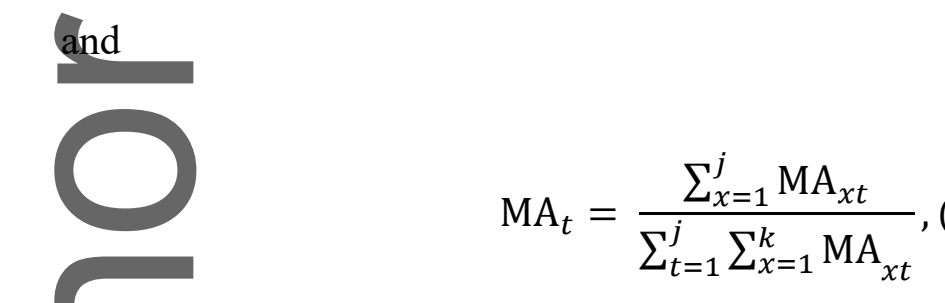

where $k$ is the number of taxa.

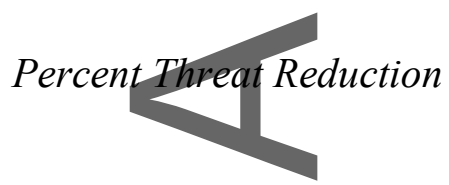

The overall threat impact was calculated by summing the impact scores across all $j$ threats for taxon $x$, both with management $\left(I_{x t a}\right)$ and without management $\left(I_{x t c}\right)$ : 


$$
I_{x t a}=\sum_{t=1}^{j}\left(I_{t a}\right)
$$

and

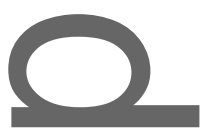

$$
I_{x t c}=\sum_{t=1}^{j}\left(I_{t c}\right), \text { respectively. (14) }
$$

Because threat impact can be lower only when management has been applied, $I_{x t a}$ is only less than $I_{x t c}$ where $M A \geq 4$ (i.e., management must have reached at least stage "v. solutions are enabling achievement but only with continued conservation intervention" [see Table 1]). Management that has had perverse outcomes (e.g. mesopredator release after apex predator control, Ritchie \& Johnson 2009) is accounted for by defining such outcomes as threats (invasive and other problematic species for mesopredator release).

For each threat, overall impact of management $\left(\mathrm{TI}_{t a}\right.$; existing threat impact) was calculated by summing threat impact for each taxon affected by the threat such that

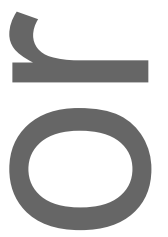

$$
\mathrm{TI}_{t a}=\sum_{x=1}^{k t}\left(I_{t a}\right)
$$

where $k_{t}$ is the number of taxa affected by threat $t$.

Overall impact without management (potential threat impact $\left[\mathrm{TI}_{t c}\right]$ ) was also calculated by summing threat impact for each taxon affected by the threat but because progress in MU and MI for each threat for each taxon is unique, $\mathrm{TI}_{t c}$ is also equal to the sum of the threat impacts of each eategory of MU or MI such that

$$
\mathrm{TI}_{t c}=\sum_{x=1}^{k}\left(I_{t c}\right)=\sum_{\mathrm{MU}=1}^{6} \sum_{x=1}^{k}\left(I_{t n}\right)=\sum_{\mathrm{MU}=1}^{7} \sum_{x=1}^{k}\left(I_{t c}\right)
$$


Actual reductions in threat impact were calculated as the percent difference between the estimated rate of decline from a threat and the rate that could be occurring had there been no management (percent threat reduction $\left[\mathrm{PTR}_{x}\right]$ ) such that
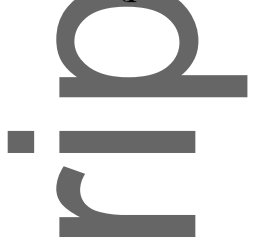

$$
\operatorname{PTR}_{x}=\frac{\left(I_{x t c}-I_{x t a}\right) \times 100}{I_{x t c}}
$$

We also calculated overall progress in reducing the impact of each threat proportional to its impact on all taxa without management such that

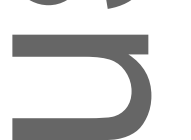

$$
\operatorname{PTR}_{t}=\frac{\left(I_{t c}-I_{t a}\right) \times 100}{I_{t c}}
$$

A worked example for three taxa that includes all formulas is provided in the Supporting Information.

Geographic distribution

Summaries for each metric were calculated for each Australian marine and terrestrial bioregion (Commonwealth of Australia 2006, Department of Sustainability, Environment, Water, Population and Communities 2012) to determine the location of threats and where research or management is either most urgent or has been most effective.

Analyses

We correlated the five metrics (response variables) against one another (using Spearman's Rank-Order Correlation), first normalizing all scores to 100. We repeated this step with 11 potential predictor variables (Supporting information) to test for collinearity (finding no correlation coefficients $>0.7$ ). We then used generalized linear modeling (multiple linear regression) to examine the effect of each of the 11 predictors on each metric. We examined a large set of models representing all possible combinations of the 11 predictors for each 
response variable (total of 5 sets, corresponding to each metric). For percent threat reduction, we only modelled the 130 taxa for which PTR $>0$, as the primary interest was to understand factors influencing management interventions that had at least started to be effective.

We then used a second-order form of Akaike's information criterion $\left(\mathrm{AIC}_{\mathrm{c}}\right)($ Burnham \& Anderson 2002) that is suitable for small sample sizes to rank and identify the best performing models in each set. A subset of models was chosen within two Akaike units from the best model (candidate set) because those at a greater distance have much less support for explaining the observed data. The final model used for inference was based on multimodel averaging of the entire candidate set. Analysis took place using the lme4 package in $\mathrm{R}$ version 3.3 .1 .

\section{Results}

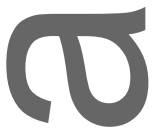

Across all 238 taxa considered, there were 181 separate threats with an average of 7.8 threats per taxon. The 1,847 combinations of threat by taxon represents 5,541 opportunities for management to have affected threat timing, extent or severity, but there was no reduction for over $85 \%$ of these threat impact parameters. For $53 \%$ of threat by taxon combinations, research is providing at least strong direction on what needs to be done to manage them, although that means that there is little or no understanding of the remainder (Fig. 1a). Just under half $(46.5 \%)$ of the threat by taxon combinations had some management under way, with a third of those in the high impact category no longer needing active management (Fig. 1b).

Despite being derived from the same data sets, correlation among the 5 metrics (research need, management need, research achievement, management achievement, and percent threat reduction) for the different taxa was generally low, with nonsignificant relationships between 
research need and research or management achievement (Supporting Information). The highest correlations were between research and management need (0.90) and between research and management achievement (0.94).

No individual model was clearly superior in explaining the observed data (Supporting Information), but certainty surrounding each effect (i.e. whether or not the confidence intervals include zero) changed only slightly among alternative models, and overall direction and effect size (regression coefficients) remained the same. Furthermore, all highly significant predictors (i.e., those where $p<0.01$ ) (see predictors in Fig. 2 that do not overlap zero) remained so in each alternate model and in most cases were present in the entire candidate set (Supporting Information).

\section{Correlates with taxon scores}

Research need was significantly influenced by range, geography, taxon type, status under the EPBC Act and conservation planning (Fig. 2a) (see Supporting Information for topperforming taxa). Research need was lower for taxa with larger ranges, for birds on islands compared with mainland birds or nonbreeding migrants and for taxa with a current recovery plan - a legislative instrument for which there are Ministerial obligations - but higher for taxa listed as threatened under the EPBC Act.

Research achievement was significantly influenced by quality of monitoring, estimated (1) detectability, mass, geography, taxonomic grouping and conservation planning (Fig. 2b). As might be expected, the better it was monitored, the greater the understanding of how to manage threats facing a taxon, though the link is not necessarily causal. High research achievement scores were also evident for heavier birds, parrots, birds on islands and those for which recovery plans are intended. Lower levels of research achievement were apparent 
among taxa that are easy to detect and for nonpasserines other than seabirds, shorebirds or parrots.

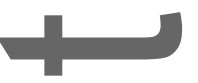

Although research need and management need were correlated, the type and influence of explanatory variables differed. Management need was significantly influenced by monitoring quality, detectability, range size, geography, taxon grouping, and EPBC listing and negatively by detectability (Fig. 2c). Management need was greater for taxa that are easier to detect, have larger ranges, are nonbreeding migrants, and are EPBC listed but lower for birds on islands, seabirds, and passerines.

Management achievement was significantly influenced by monitoring quality, detectability, geography, taxon grouping and conservation planning (Fig. 2d). It was greatest among taxa with high quality monitoring, on islands and among seabirds and parrots but lowest among highly detectable species, shorebirds and those with an old recovery plan.

Threat reduction had been achieved in over half of all taxa $(55 \% ; n=130)$. Percent threat reduction was particularly high for threatened birds on continental islands but low for critically endangered taxa (Fig. 2e).

\section{Correlates with threat scores}

Invasive species comprised the major threat class with the highest scores for all need and achievement metrics (Fig. 3), particularly cats (Felis catus) and black rats (Rattus rattus), (Supporting Information). Urban development, agriculture, biological resource use and natural system modification all had moderate scores. Pollution and climate change or extreme weather measures (particularly more intense or frequent droughts) have high need scores but almost no achievements for either research or management. 
The highest percent threat reduction as a result of management since 1900 has been from agriculture, largely because critical habitat that could have been cleared was reserved for the purpose of conservation. The almost equally high score for geological events was an artefact of a small sample size; in this case, translocation of Hutton's Shearwater (Puffinus huttoni) to spread risk to breeding sites was remarkably timely (McSweeney 2016). Moderately high percent threat reduction scores were achieved for urban development, mining, human disturbance and invasive species. No threat reduction was achieved for pollution, climate change, or extreme weather.

Geographic spread of Research and Management Need and Achievement Geographically the highest density of threatened taxa occurs in seas off southern Australia, particularly southeast of Tasmania, while the terrestrial bioregions with the highest numbers of threatened taxa are in the coastal parts of northern and eastern Australia. Research need is rond greatest around the coasts of mainland Australia, reflecting the urgency in understanding how to contain the threats to migratory shorebirds (Fig. 4a). In contrast, research achievement (Fig. 4b) appears to reflect progress in understanding the threats facing southern seabirds. Management need (Fig. 4c) remains high in the southeastern marine zone as well as for coastal birds while management achievement (Fig. 4d) has been greatest for Macquarie Island, which is also where the greatest overall percent reduction in threat impact has been achieved (Fig. 4e).

\section{Discussion}

Used appropriately, these metrics can provide an overview for an entire class of animals for a whole continent, the needs for research and management for each threat to each taxon, the achievements to date in alleviating those threats and the percent change in impact on the 
ground. This information can be generated for any taxon or group of taxa, any threat or group of threats and at any geographical scale, allowing prioritisation of action and reporting.

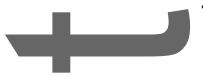

While acknowledging the need for caution and, preferably, triangulation in employing the analyses to determine priorities at a taxon level rather than between taxa, we see 4 main merits in our approach.

The relative ease with which assessments of progress can be completed. Understanding which threats pertain to a taxon and their impact, based on threat timing, extent and severity, are recommended to be assessed as part of any standard IUCN Red List assessment (IUCN 2013). To calculate our metrics requires only 3 further judgements for each threat - an assessment of the impact of a threat had no management occurred, the level of understanding of how to manage each of the threats affecting a taxon, and the extent to which that knowledge is being applied.

The metrics allow, for the first time, evidence-based prioritization of research or management within or between taxa. Within a taxon, ranking of research and management needs for different threats can potentially contribute to recovery planning. Comparisons among taxa or threats can indicate where investments are most likely to have an impact. Amelioration of a threat that affects multiple taxa could have higher priority because knowledge of threat management should be transferable among similar taxa.

Incorporation of both needs and achievement in the same set of metrics can help practitioners balance the scale of problems ahead with what has been achieved: encouragement is critical to conservation advocacy (Garnett \& Lindenmayer 2011). Our framework and others currently in development (i.e., the IUCN Green List of Species [Akçakaya et al. 2018]) explicitly incorporated this approach. It can be easy to forget how effectively hunting has 
been reduced as a threat in Australia, especially when compared internationally (Maxwell et al. 2016). Similarly, protected areas and legislation are limiting clearing of threatened taxon habitat, even if habitat loss continues to affect some threatened taxa.

The adoption of an explicit counterfactual approach allows for more comprehensive assessment of the impact of conservation. In a world where overall biodiversity declines are the norm, narratiyes of conservation success tend to focus on particular case studies. Our approach builds on and extends previous efforts to provide more systematic and quantitative metrics of the impact of conservation efforts across an entire group of taxa (Butchart et al. 2005; Hoffmann et al. 2010, 2014).

\section{Opportunities for metric development}

There are many opportunities to refine or improve the method we have proposed. We adopted a simple linear approach to scoring progress in research and management, but there is potential to explore this more systematically to ensure each step is conceptually of equal significance. Rules could be developed to accommodate synergies or overlaps in threat impact. Sensitivity analyses could explore the impact of uncertainties in any of the parameters. Threat impacts could be weighted to reflect their reversibility. We prioritized minimizing threats across all threatened taxa by giving equal weight to all threats and all taxa with the same impact score. However, weighting taxa by IUCN Red List category of extinction risk could emphasise extinction minimization (see Supporting Information). A knowledge weighting could reduce potential bias arising from more threats being identified for the most elosely studied taxa. Sometimes the process may need to be undertaken in several stages. While counterfactual assessments of threat impact, knowledge of how to manage threats and the extent to which that knowledge is being applied are reasonably easy to score for narrow ranging taxa or threats with narrow scope, wide-ranging taxa or large 
scope threats are more challenging. In such cases, spatial variation in the answers (e.g., between countries) may need to be assessed regionally then aggregated to the taxon level.<smiles>CC1(C)CCCCC1</smiles>

The application of these metrics can be extended. For example, the same methodology could be applied to locations or populations of a single taxon to clarify spatial variation in performance of management interventions. Data on the level of investment applied to reduce the impact of each threat could allow calculation of cost-effectiveness in conservation investment, which can help with prioritization (Joseph et al. 2009). Metrics based on the same principles could be extended to the governance and social drivers of conservation performance and link threat management to the types of action taken to reduce those threats. The metrics presented here could also be used in tandem with other indicators to evaluate whether threat reduction is associated with changes in taxon status, for example, extinction risk (red list) and recovery (IUCN Green List of Species [Akçakaya et al. 2018]). With all refinements, the basic premise that metrics are indicative, not definitive, should not be forgotten

\section{Implications for Australian birds}

The results show few threatened Australian bird taxa have had all threats reduced to a stage where they no longer need at least some form of ongoing management to persist. But there have been some remarkable successes, such as eradication of invasive species on some islands. Most results were unsurprising, but have never before been summarised in ways that allow comparison of performance across all of Australia's threatened birds. The success of several island conservation programs is well documented (Frith 2013; Priddell \& Carlile 2009; Woinarskiet al. 2016; Springer 2018), but their national context has not been fully appreciated. Our geographical summaries highlight the enormity of the achievement on Macquarie Island, the critical nature of quarantine to Heard Island and the importance of the 
research aimed at reducing the impacts of fishing on seabirds, although implementation of that knowledge has been challenging (Baker \& Robertson 2018). These achievements contrast with the ongoing severe threats to migratory shorebirds, mainly outside Australia (Clemens et al.2016) and the mounting evidence of the threat posed by cats (Woinarski et al. 2017).

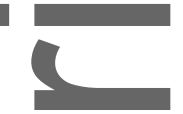

Also unsurprising is the critical role played by monitoring in both research and management achievement, reinforcing pleas that monitoring be given increased attention and resourcing (Legge et al.2018). Also, while intuitive, the link between research and management performance in conservation is rarely quantified (Cohen et al. 2002).

One notable finding was that having a current recovery plan is better than having no plan in terms of achievements in both research and management. Encouragingly, even having an old plan is associated with threat reduction. While it may be that taxa receiving research and rencicis management attention are more likely to have a recovery plan written, and noting that we have not demonstrated cause and effect, the apparent importance of recovery plans contrasts with the conclusions of Bottrill et al. (2011). This may be partly because they looked only for improvements in EPBC status, which was very rare in the first 10 years of the EPBC Act's existence (Garnett 2013), and possibly because recovery planning for birds is more effective than the average across taxa. In the United States (Suckling et al. 2016), recovery plans had more impact for bjrds than for other groups because they received attention earlier, so actions have had more time to take effect. Our results also suggest that performance of another element of the EPBC Act, listed key threatening processes and threat abatement plans (Department of the Environment and Energy 2018), warrant investigation with our approach once data are available on other faunal groups they are meant to benefit. 
Notwithstanding the experimental nature of the metrics as presented here, the results from their application to Australian birds carry important messages. The first is that the contrast between current and counterfactual threat impacts suggests that the conservation status of Australian threatened birds is far better than it would be had there not been investment in research, management and policy over many decades, starting with hunting restrictions and the declaration of protected areas in the $19^{\text {th }}$ century. In recent years there have also been some highly suecessful interventions to control or eradicate invasive species, particularly on some islands. Second, much remains to be done if extinctions are to be prevented and sustained conservation of Australian threatened birds is to be achieved. Given how much has been achieved, ongoing investment is warranted to complete the task. The metrics presented here can be used to measure that progress.

\section{Acknowledgments}

We are grateful to all those who provided input into the assessment of threats and progress, including D. Bain, L. Baker, D. Baker-Gabb, P. Bell, A. Black, L. Bluff, H. Bower, A. Briggs, P.Buosi, T. Burnard, H. Campbell, N. Carlile, M. Christian, R. Clarke, S. Comer, A. Desmond, N. Dunlop, D. Egan, H. Ford, D. Geering, I. Gynther, J, Hardy, R. Heinsohn, M. Herring, B. Hill, F. Hill, R. Hill, M. Holdsworth, W. Houston, V. Hurley, R. Johnstone, M. Mathieson, P. Mawson, S. Murphy, M. Newman, L. Ortiz, C. Pavey, M. Pickett, D. Portelli, I. Radford, K. Ravich, M. Read, J. Schoenjahn, R. Seaton, J. Smith, J. Sommerfeld, D. Stewart, C. Surman, M. Todd, T. Vale, E. Vanderduys, T. Vigilante, S. Ward, M. Weston, and E. Woehler We also thank the many managers who have been successfully applying management principles to Australian birds over many decades. This project was partially funded by the National Environment Science Program's Threatened Species Recovery Hub and Charles Darwin University. 


\section{Literature Cited}

Akçakaya HR, et al. 2018. Quantifying species recovery and conservation success to develop an IUCN Green List of Species. Conservation Biology. doi 10.1111/cobi.13112

Australian Government. 2017. Significant impact guidelines 1.1 - matters of national environmental significance. Department of the Environment and Energy, Canberra, Available from http://www.environment.gov.au/epbc/publications/significant-impactguidelines-11-matters-national-environmental-significance (accessed March, 2018).

Baker GB, Robertson G. 2018. Management of seabird bycatch leads to sustainable fisheries and seabird populations Pages 23-31 in ST Garnett, P Latch, DB Lindenmayer, JCZ

Woinarski, editors. Recovering Australian threatened species: a book of hope. CSIRO Publishing, Melbourne.

Bottrill MC, Walsh JC, Watson JE, Joseph LN, Ortega-Argueta A, Possingham HP. 2011. Does recovery planning improve the status of threatened species? Biological Conservation 144:1595-1601.

Burnham KP, Anderson DR. 2002 Model selection and inference: a practical informationtheoretic approach, New York, Springer.

Butchart SH, Akęakaya HR, Chanson J, Baillie JE, Collen B, Quader S, Turner WR, Amin R, Stuart SN, Hilton-Taylor C. 2007. Improvements to the Red List Index. PloS one 2: (e140) DOI: 10.1371/journal.pone.0000140.

ButchartSH, Stattersfield AJ, Baillie J, Bennun LA, Stuart SN, Akçakaya HR, Hilton-Taylor C, Mace GM. 2005. Using red list indices to measure progress towards the 2010 
target and beyond. Philosophical Transactions of the Royal Society of London B:

Biological Sciences 360:255-268.

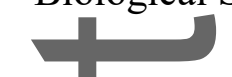

Clemens RS, et al 2016. Continental-scale decreases in shorebird populations in Australia.

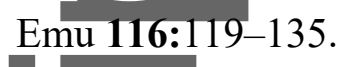

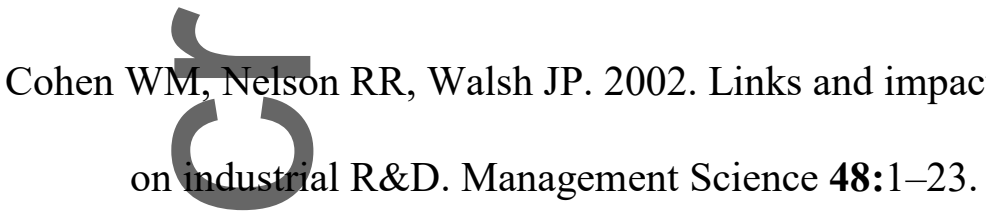

Commonwealth of Australia. 2006. A guide to the Integrated Marine and Coastal

Regionalisation of Australia Version 4.0. Canberra: Department of the Environment and Heritage, Canberra http://www.environment.gov.au/resource/guide-integratedmarine-and-coastal-regionalisation-australia-version-40-june-2006-imcra (Accessed September 2017).

Côté IM, Darling ES, Brown CJ. 2016. Interactions among ecosystem stressors and their importance in conservation. Proceedings of the Royal Society B 283:2015-2592.

Daniels RRJ, Hedge M, Joshi NV, Gadgil M (1991) Assigning conservation value: a casestudy from India. Conservation Biology 5:464-475.

Del Hoyo J, Collar NJ. 2016. HBW and BirdLife International illustrated checklist of the birds of the world. Volume 2. Lynx Edicions, Barcelona.

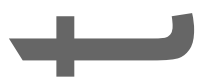

Department of Sustainability, Environment, Water, Population and Communities, 2012. IBRA 7: Interim Biogeographic Regionalisation for Australia. Department of Environment and Energy, Canberra. Available from http://www.environment.gov.au/land/nrs/science/ibra\#ibra. (Accessed September 2017). 
Department of the Environment and Energy. 2017. EPBC Act List of Threatened Fauna.

Department of Environment and Energy, Canberra. Available from

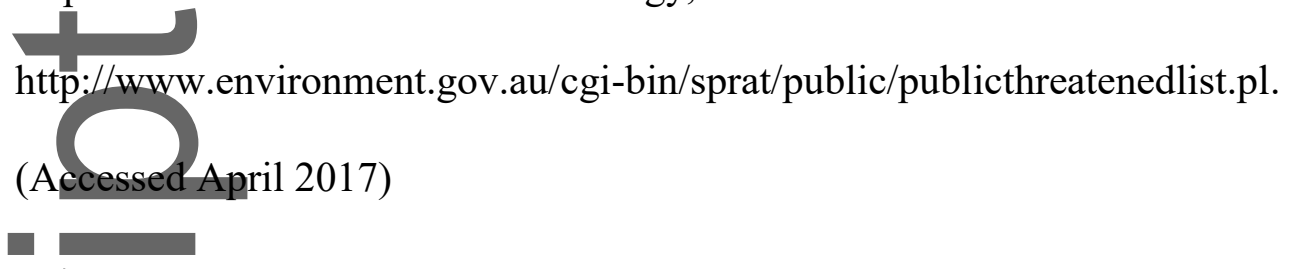

Department of the Environment and Energy. 2018. Listed Key Threatening Processes.

Department of Environment and Energy, Canberra. Available from

http://Www.environment.gov.au/cgi-bin/sprat/public/publicgetkeythreats.pl.

(Accessed April 2018).

(acessect

Ferraro PJ. 2009. Counterfactual thinking and impact evaluation in environmental policy.

New Directions for Evaluation 122:75-84.

Ferraro PJ, Pattanayak SK. 2006. Money for nothing? A call for empirical evaluation of biodiversity conservation investments. PLOS Biology 4:(e105) DOI:

10.1371/journal.pbio.0040105.

Frith C. 2013. The Woodhen: A flightless island bird defying extinction. CSIRO Publishing, Melbourne.

Garnett ST. 1992. The Action Plan for Australian Birds. Australian National Parks and Wildlife Service, Canberra.

Garnett ST. 2013. Making Australian threatened species legislation more effective and efficient. Charles Darwin University, Darwin.

Garnett ST. Geyle HM. 2018. The extent and adequacy of monitoring for Australian threatened bird species. Pages 43-55 in S Legge, DB Lindenmayer, NM Robinson, 
BC Scheele, DM Southwell, BA Wintle, editors. Monitoring threatened species and ecological communities.. CSIRO Publishing, Melbourne.

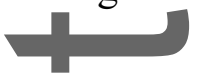

Garnett S, Christidis L. 2007. Implications of changing species definitions for bird conservation purposes. Bird Conservation International 17:187-195.

Garnett ST, Crowley GM, and Balmford A. 2003. The costs and effectiveness of funding the conservation of Australian threatened birds. BioScience 53:658-665.

Garnett ST, et al. 2015. Biological, ecological, conservation and legal information for all species and subspecies of Australian bird. Scientific Data 2:1590061.

Garnett ST, et al. 2013. Climate change adaptation strategies for Australian birds. National Climate Change Adaptation Research Facility, Gold Coast.

Garnett ST, Lindenmayer DB. 2011. Conservation science must engender hope to succeed. Trends in Ecology \& Evolution 26:59-60.

Garnett ST, Szabo JK, Dutson G. 2011. The Action Plan for Australian Birds 2011. CSIRO, Melbourne.

Hoffmann, M., et al. (2010) The impact and shortfall of conservation on the status of the world's vertebrates. Science 330: 1503-1509.

Hoffmann, M., Duckworth, J.W., Holmes, K., Mallon, D.P., Rodrigues, A.S. and Stuart, S.N., 2015. The difference conservation makes to extinction risk of the world's ungulates. Conservation Biology 29:1303-1313.

IUCN (International Union for Conservation of Nature). 2012. Threats classification scheme. Version 3.2. IUCN. Gland, Switzerland. Available from 
http://www.iucnredlist.org/technical-documents/classification-schemes/threatsclassification-scheme. (Accessed April 2018).

(1)

IUCN (International Union for Conservation of Nature). 2013. Documentation standards and consistency checks for IUCN Red List assessments and species accounts. Version 2.

Adopted by the IUCN Red List Committee and IUCN SSC Steering Committee.

IUCN, Gland, Switzerland. Available from

http://www.iucnredlist.org/documents/RL_Standards_Consistency.pdf (Accessed Apri1 2018).

Joseph LN, Maloney RF, Possingham HP. 2009. Optimal allocation of resources among threatened species: a project prioritization protocol. Conservation biology 23:328-

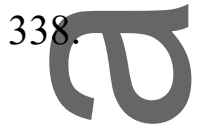

Kapos V, et al. 2008. Calibrating conservation: new tools for measuring success.

Conservation Letters 1:155-164.

Legge, S., Lindenmayer, D., Robinson, N., Scheele, B., Southwell, D., and Wintle, B. (Eds) 2018. Monitoring Threatened Species and Ecological Communities. CSIRO

Publishing: Melbourne.

Maxwell SL, Fuller RA, Brooks TM, Watson J.E. 2016. Biodiversity: The ravages of guns, nets and bulldozers. Nature 536:143-145.

McSweeney P. 2016. At risk bird, Hutton's shearwater, has lost an estimated quarter of their population. http://www.stuff.co.nz/national/nz-earthquake/86547893/at-risk-birdhuttons-shearwater-has-lost-an-estimated-quarter-of-their-Population. 
Meredith HM, St John F, Collen B, Black SA, Griffiths RA. 2018. Practitioner and scientist perceptions of successful amphibian conservation. Conservation Biology 32:366-375. r.

Priddel D, Carlile N. 2009. Key elements in achieving a successful recovery programme: A discussion illustrated by the Gould's Petrel case study. Ecological Management \& Restoration 10: doi 10.1111/j.1442-8903.2009.00460.x.

Redford KH, et al. 2011. What does it mean to successfully conserve a (vertebrate) species? BioScience 61:39-48.

Reid N, Lundy MG, Hayden B, Lynn D, Marnell F, McDonald RA,Montgomery WI. 2013. Detecting detectability: identifying and correcting bias in binary wildlife surveys demonstrates their potential impact on conservation assessments. European Journal of Wildlife Research 59:869 -879.Ritchie EG, Johnson CN. 2009. Predator interactions, mesopredator release and biodiversity conservation. Ecology letters 12:982--998.

Royal Society for the Protection of Birds (RSPB). 2017. Safeguarding species: a strategy for species recovery. Royal Society for the Protection of Birds, Sandy, U.K. Available from https://ww2.rspb.org.uk/globalassets/downloads/documents/conservation-sustainability/safeguarding/safeguarding-species.pdf. (Accessed August 2017)

Salafsky N, Margoluis R, 1999. Threat Reduction Assessment: a Practical and Cost Effective Approach to Evaluating Conservation and Development Projects. Conservation Biology 13:830-841.

Sanderson FJ, Pople RG, Ieronymidou C, Burfield IJ, Gregory RD, Willis SG, Howard C, Stephens PA, Beresford AE, Donald PF. 2016. Assessing the performance of EU 
nature legislation in protecting target bird species in an era of climate change.

Conservation Letters 9:172-180.

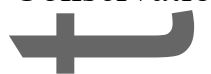

Springer K 2018. Eradication of invasive species on Macquarie Island to restore the natural ecosystem. Pages 13-22 in ST Garnett, P Latch, DB Lindenmayer, JCZ Woinarski, editors. Recovering Australian threatened species: a book of hope. CSIRO

Publishing, Melbourne.

Suckling KF, Mehrhoff LA, Beam R, Hartl B. 2016. A Wild Success: A Systematic Review of Bird Recovery under the Endangered Species Act. Tucson, AZ: Center for Biological Diversity.

Sutherland WJ, Pullin AS, Dolman PM, Knight TM. 2004. The need for evidence-based conservation. Trends in Ecology \& Evolution 19:305-308.

Schwartz MW, Deiner K, Forrester T, Grof-Tisza P, Muir MJ, Santos MJ, Souza LE, Wilkerson ML, Zylberberg M. 2012. Perspectives on the Open Standards for the Practice of Conservation. Biological conservation 155:169-177.

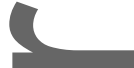

Szabo JK, Butchart SHM, Possingham HP, Garnett ST. 2012. Adapting global biodiversity indicators to the national scale: a Red List Index for Australian birds. Biological Conservation 148:61-68. doi 10.1016/j.biocon.2012.01.062.

Westwood A, Reuchlin-Hugenholtz E, Keith DM. 2014. Re-defining recovery: A generalized framework for assessing species recovery. Biological Conservation 172:155-162.

Woinarski JCZ, et al. 2017. How many birds are killed by cats in Australia? Biological Conservation 241:76-87. 
Woinarski JCZ, et al. 2016. Conservation status and reintroduction of the Cocos Buff-banded Rail, Gallirallus philippensis andrewsi. Emu 116:32-40.

U.S. Fish and Wildlife Service. 1983. Endangered and threatened species listing and recovery priority guidelines. Federal Register 43(184):43098-43105.

Zadeh LA. 1965. Fuzzy Sets. Information and Control 8:338-353.

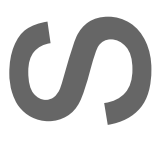

Table 1. Indicators of progress in understanding threats or implementing management and weights used to characterize needs for or achievements in research or management.

\begin{tabular}{|c|c|c|}
\hline \multirow[b]{2}{*}{ Indicator } & \multicolumn{2}{|c|}{ Weighting } \\
\hline & need & achievement \\
\hline \multirow{2}{*}{\multicolumn{3}{|c|}{$\begin{array}{l}\text { Understanding } \\
\text { i. management understanding }\end{array}$}} \\
\hline & & \\
\hline ii. no knowledge and no research & 6 & 0 \\
\hline $\begin{array}{l}\text { iii. research underway or completed but limited understanding on } \\
\text { how to manage threat }\end{array}$ & 5 & 1 \\
\hline iv. researeh provided strong direction on how to manage threat & 4 & 2 \\
\hline v. solutions trialed; work initiated recently & 3 & 3 \\
\hline $\begin{array}{l}\text { vi. trial management under way; no clear evidence yet that it can } \\
\text { deliver objectives }\end{array}$ & 2 & 4 \\
\hline $\begin{array}{l}\text { vii. trial management providing clear evidence it can deliver } \\
\text { objectives }\end{array}$ & 1 & 5 \\
\hline $\begin{array}{l}\text { viii. research complete and being applied or ongoing research } \\
\text { associated with adaptive management of threat }\end{array}$ & 0 & 6 \\
\hline
\end{tabular}

\section{Implementation}

i. no management

ii. management limited to trials

$7 \quad 0$

iii. work has been initiated to roll out solutions where threat

$6 \quad 1$

applies across the taxon's range

52

iv. solutions have been adopted; too early to demonstrate success

$4 \quad 3$




\begin{tabular}{lll} 
& \multicolumn{2}{c}{ Weighting } \\
\cline { 2 - 3 } Indicator & need & achievement \\
\hline $\begin{array}{l}\text { v. solutions are enabling achievement but only with continued } \\
\text { conservation intervention } \\
\begin{array}{l}\text { vi. solutions enabling achievement with minimal conservation } \\
\text { intervention }\end{array}\end{array}$ & 3 & 4 \\
$\begin{array}{l}\text { vii. good evidence that solutions are enabling achievement with } \\
\text { little or no conservation intervention }\end{array}$ & 1 & 6 \\
\begin{tabular}{l} 
viii. threat no longer needs management \\
\hline
\end{tabular} & 0 & 7 \\
\hline
\end{tabular}

Table 2. Weights accorded to the impact ${ }^{\mathrm{a}}$ of continuing threats based on their extent (i.e., the proportion of the total population affected) and their severity (i.e., the rate of population decline caused by the threat within its scope).

\begin{tabular}{|c|c|c|c|c|c|}
\hline \multirow[b]{2}{*}{ Extent } & \multicolumn{5}{|c|}{ Severity } \\
\hline & $\begin{array}{l}\text { y rapid } \\
\text { ecline }\end{array}$ & rapid decline & $\begin{array}{l}\text { slow, } \\
\text { significant } \\
\text { decline }^{b}\end{array}$ & $\begin{array}{c}\text { negligible } \\
\text { decline }\end{array}$ & no decline \\
\hline Whole & $63.0 * *$ & $23.5^{*}$ & $10.4^{*}$ & $1.4 \dagger$ & $0.0 \dagger$ \\
\hline Majorit & $52.0 * *$ & $18.0 *$ & $9.0^{\wedge}$ & $1.1 \dagger$ & $0.0 \dagger$ \\
\hline Minority & $24.9 *$ & $7.3^{\wedge}$ & $4.8^{\wedge}$ & $0.5 \dagger$ & $0.0 \dagger$ \\
\hline Negligibl & $0.5 \dagger$ & $0.1 \uparrow$ & $0.1 \dagger$ & $0.0 \dagger$ & $0.0 \dagger$ \\
\hline
\end{tabular}

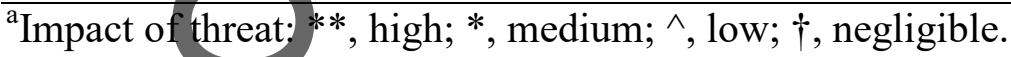

${ }^{\mathrm{b}}$ Threats likely to cause fluctuations in populations are given the same weighting as those causing slow significant declines.

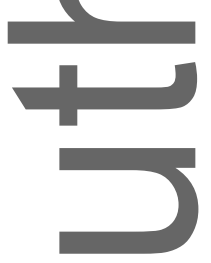

Figure 1. Level of progress in (a) understanding and (b) managing threats to Australian birds relative to the percentage of all threats identified for different taxa and the impact they are 
having on the birds (black, high-impact threats, population declines of $\geq 50 \%$; dark gray, medium, 10-50\%; light gray, low , 2-10\%; white, negligible, $<2 \%$ ).
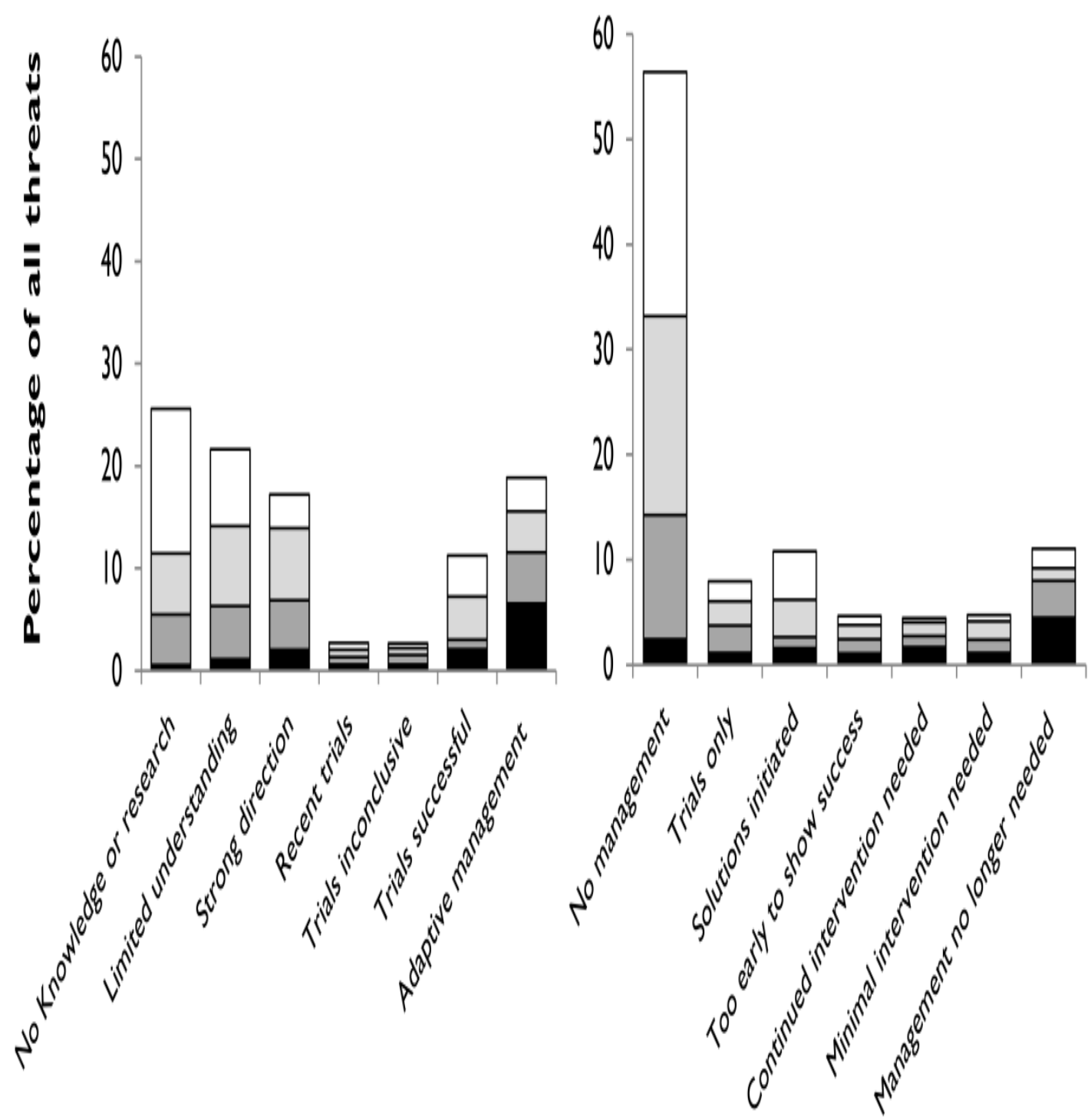

(a) Progress in understanding threats

(b) Progress in managing threats

Figure 2. Standardized regression coefficients and 95\% CIs for predictors of (a) research need, (b) research achievement, (c) management need, (d) management achievement (for all 
$n=236$ threatened Australian birds), and (e) percent threat reduction (for all $n=130$ threatened

Australian birds with percent threat reduction $>0$ ).

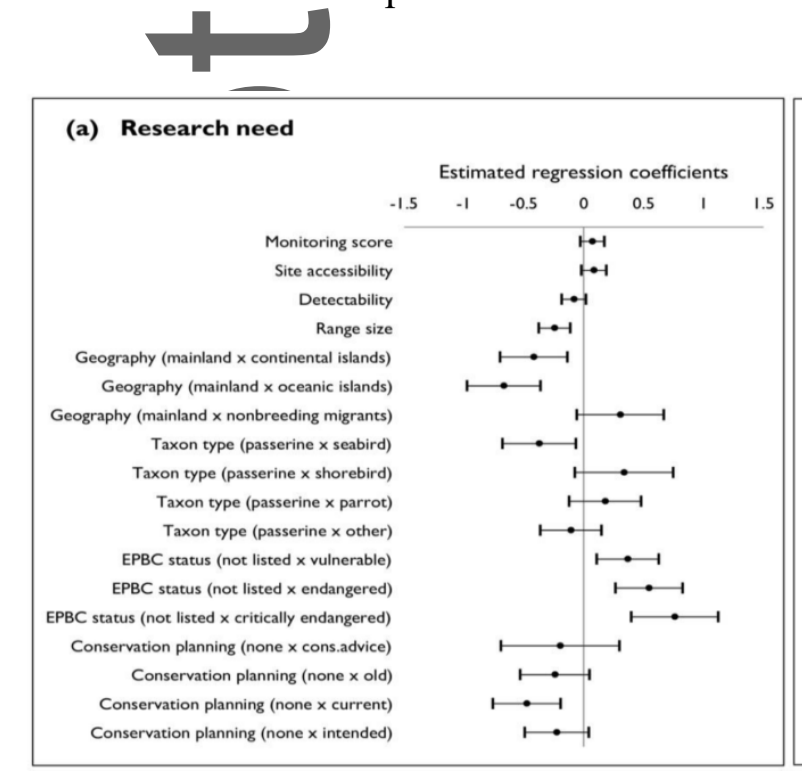

(b) Research achievement
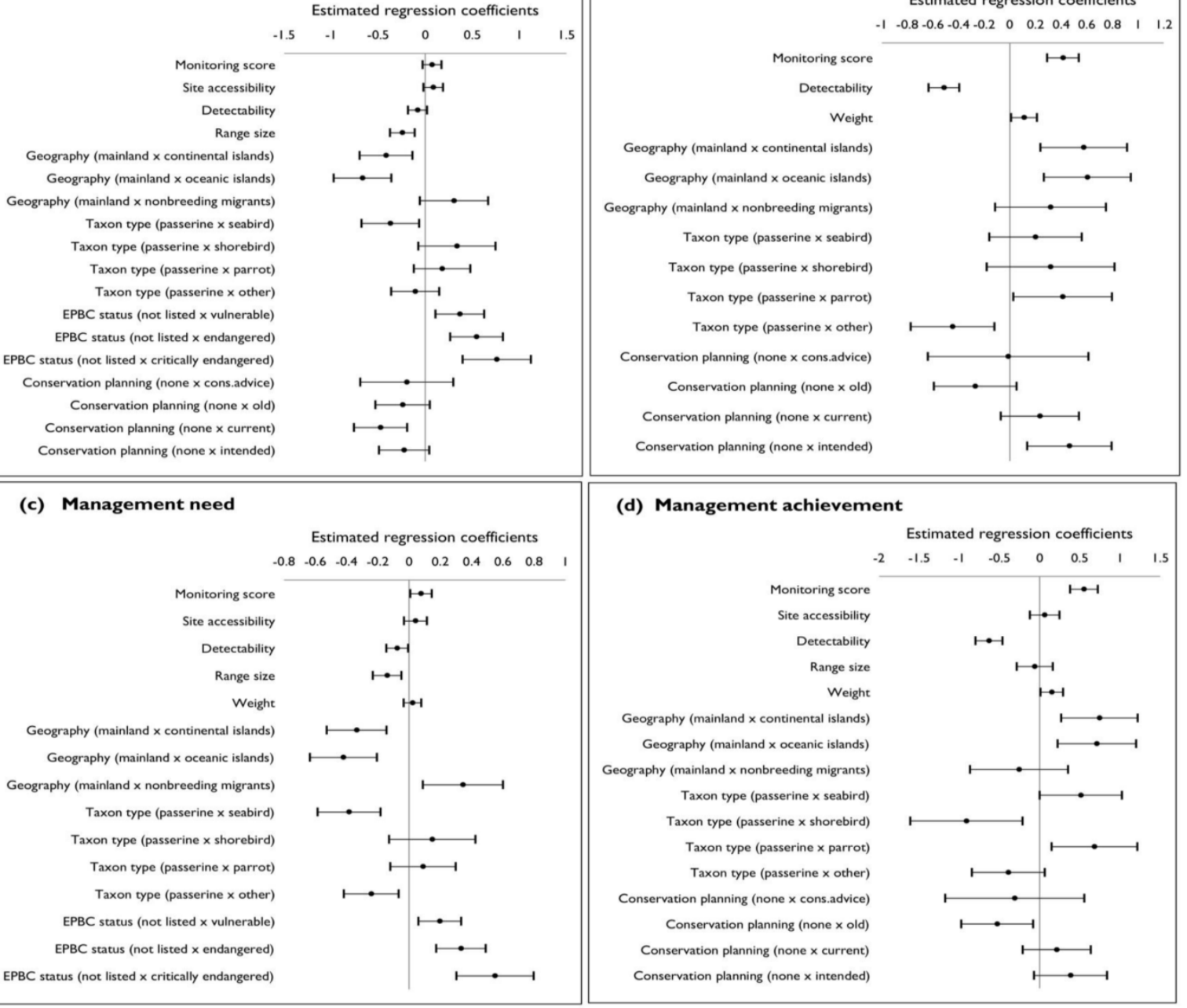

(d) Management achievement

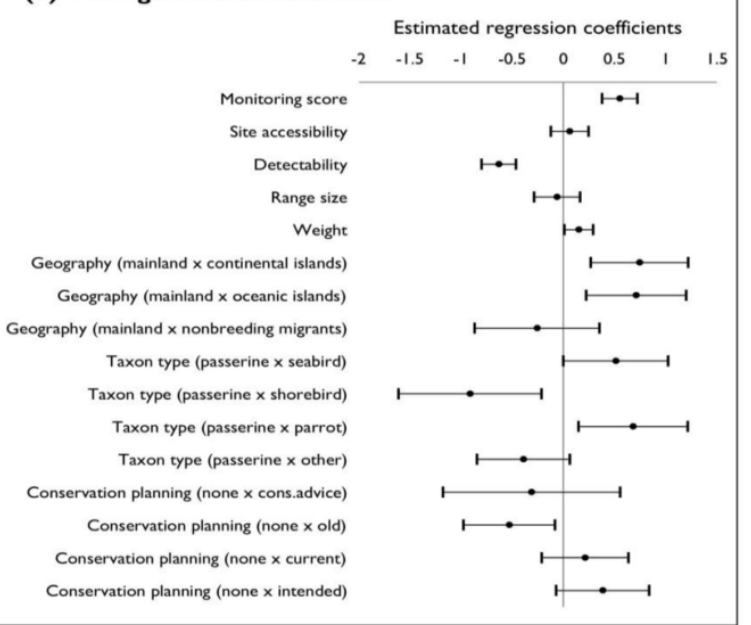

(e) Percent threat reduction

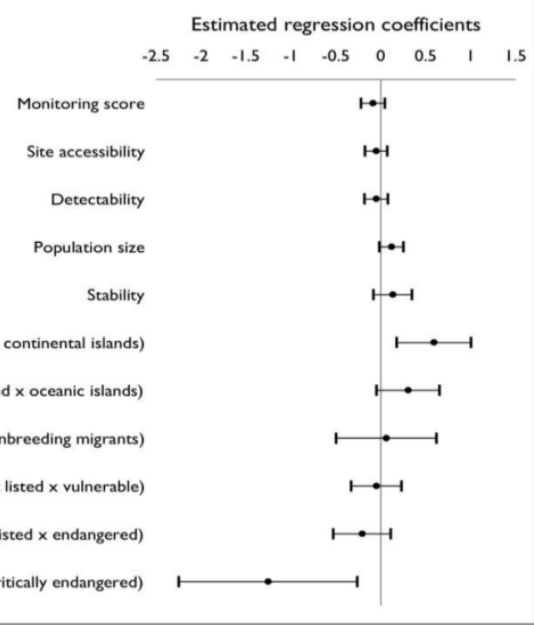

This article is protected by copyright. All rights reserved. 
Figure 3. Normalized values of performance for understanding and managing research and management and percent reduction in each threat class for the 12 major threat classes affecting Australian threatened birds (the total number of birds affected by each threat class in parentheses)
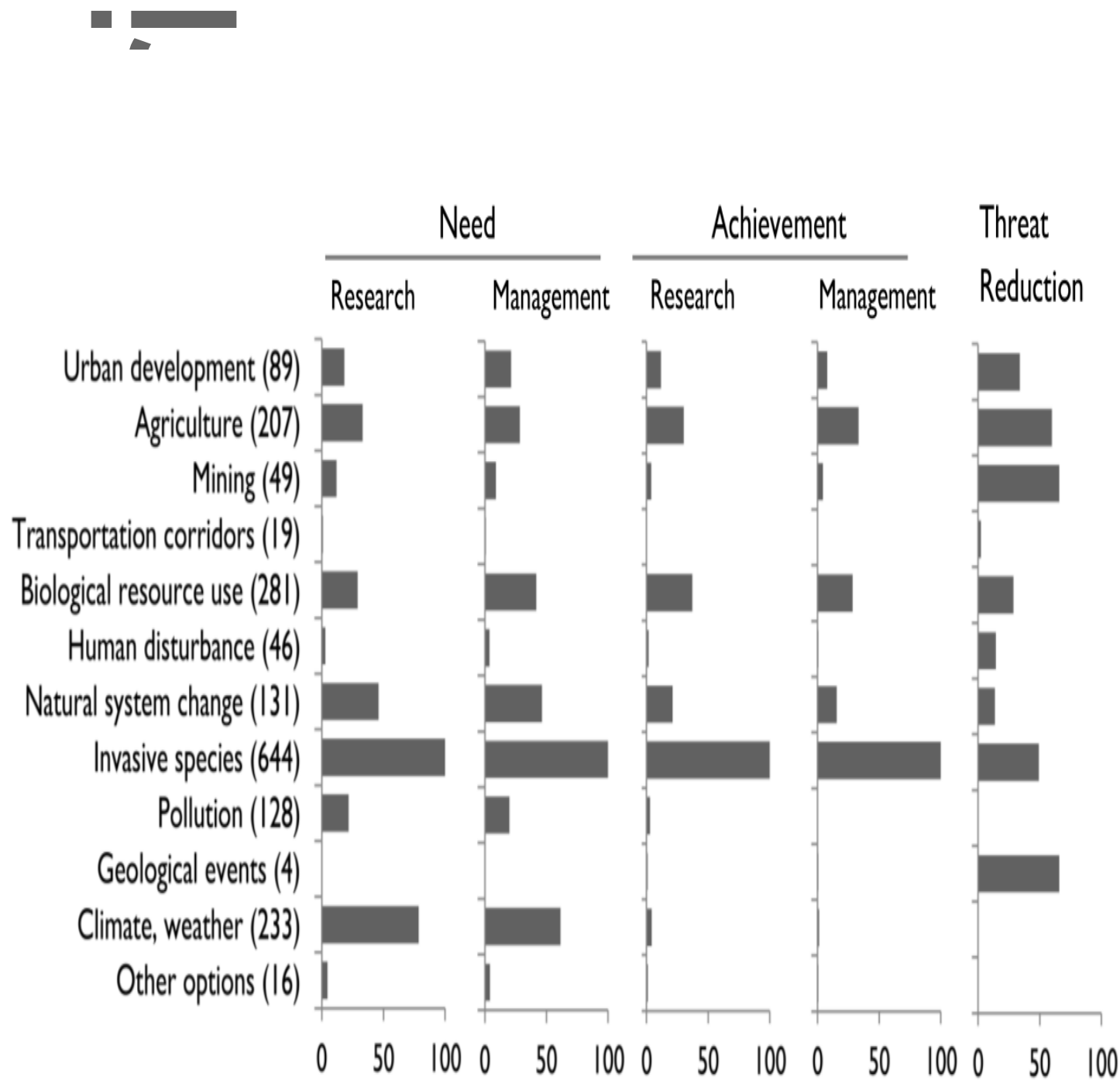

Figure 4. Normalized bioregional totals for predictors of (a) research need, (b) research achievement, (c) management need, (d) management achievement (for all $n=236$ threatened australian birds), and (e) percent threat reduction (for all $n=130$ threatened Australian birds with percent threat reduction $>0)(\mathrm{CK}$, Cocos Keeling Islands; CI, Christmas Island; HM, 
Heard and Mcdonald Islands; MQ, Macquarie Island; LH, Lord Howe Island; NI, Norfolk

Island; TSI, Torres Strait Islands).
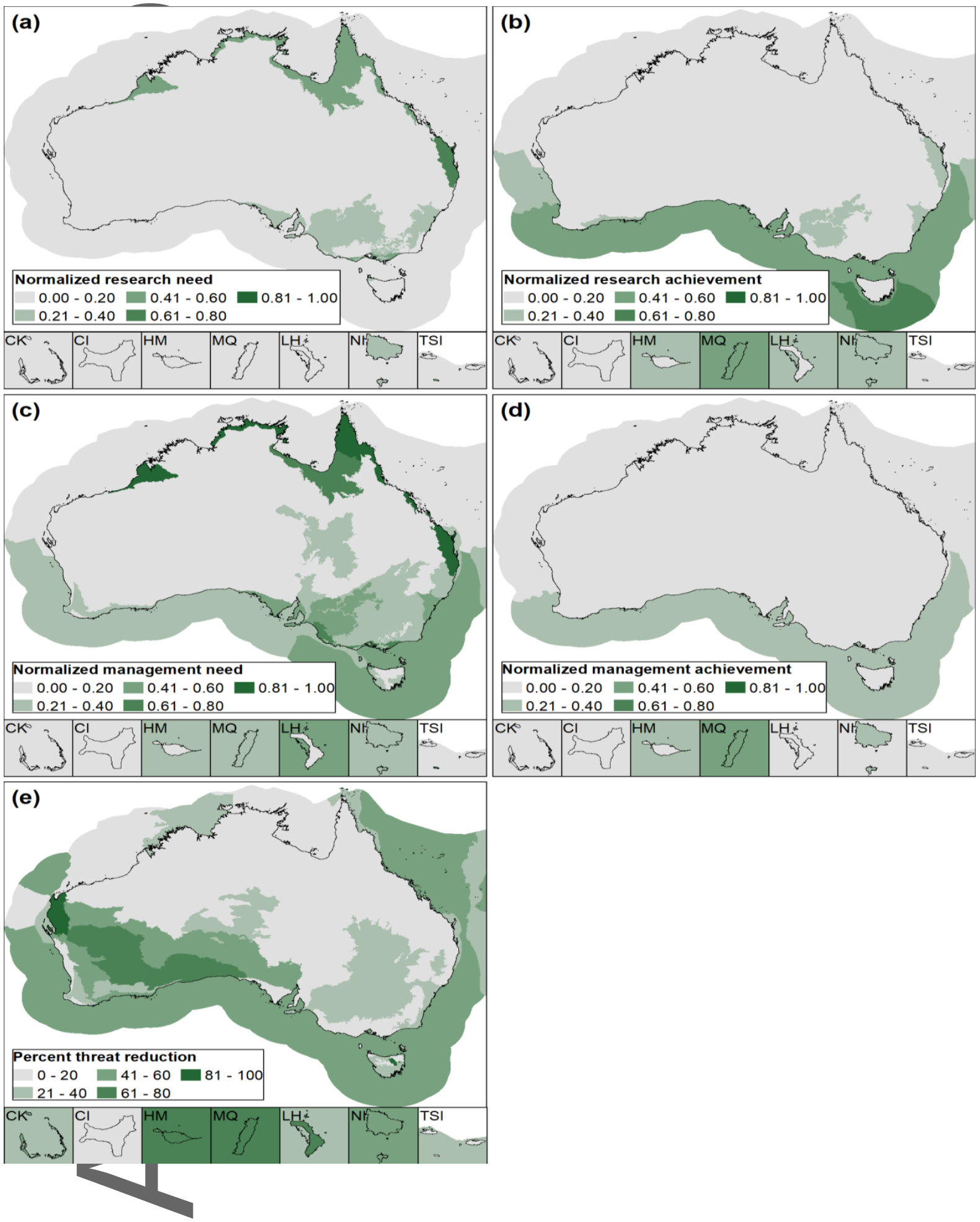

This article is protected by copyright. All rights reserved. 

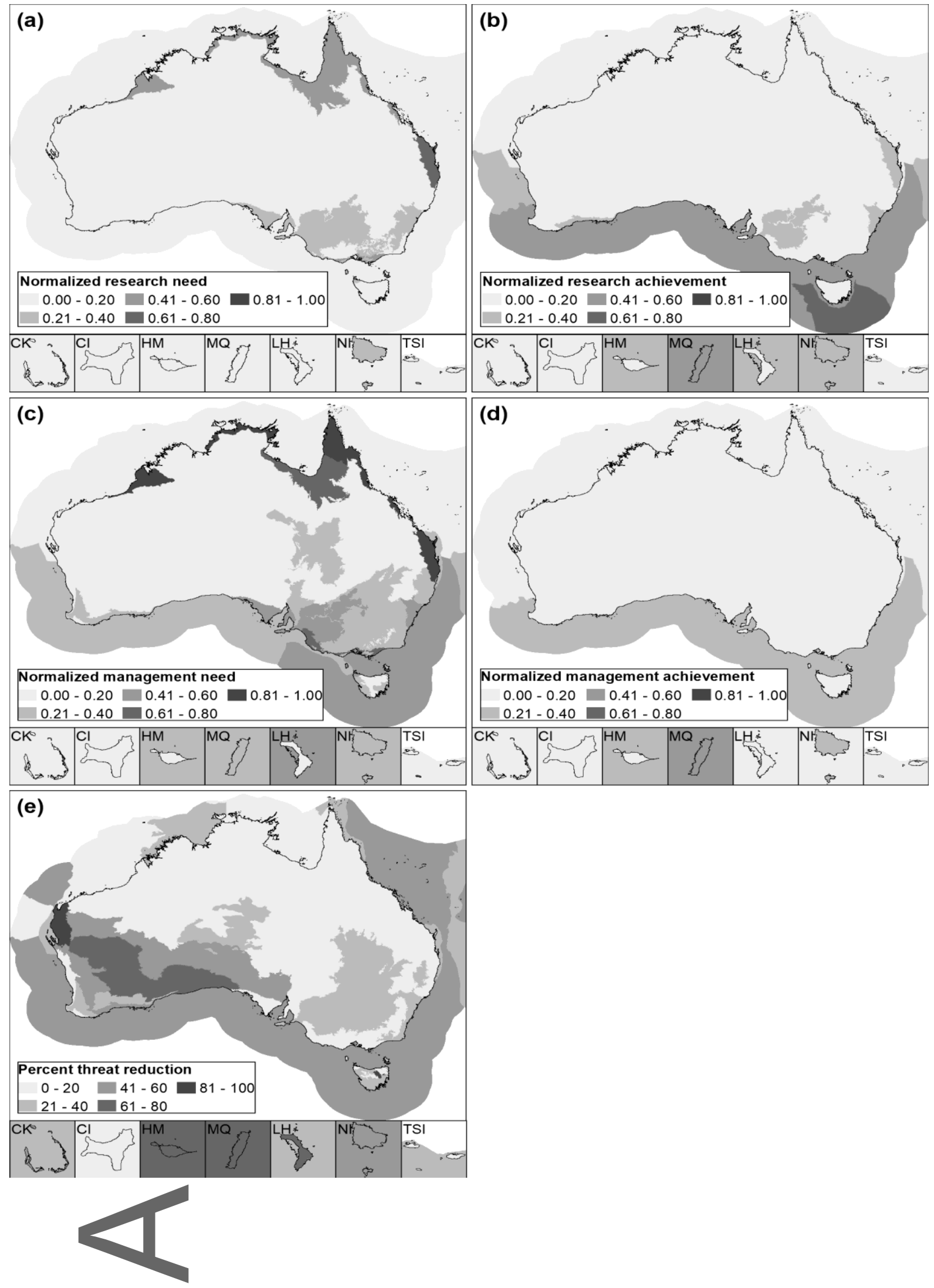

This article is protected by copyright. All rights reserved. 


\section{University Library}

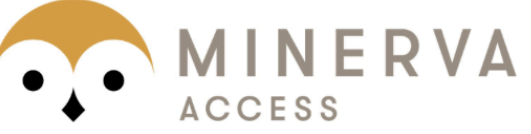

A gateway to Melbourne's research publications

Minerva Access is the Institutional Repository of The University of Melbourne

\section{Author/s:}

Garnett, ST;Butchart, SHM;Baker, GB;Bayraktarov, E;Buchanan, KL;Burbidge, AA;Chauvenet, ALM;Christidis, L;Ehmke, G;Grace, M;Hoccom, DG;Legge, SM;Leiper, I;Lindenmayer, DB;Loyn, RH;Maron, M;McDonald, P;Menkhorst, P;Possingham, HP;Radford, J;Reside, AE;Watson, DM;Watson, JEM;Wintle, B;Woinarski, JCZ;Geyle, HM

Title:

Metrics of progress in the understanding and management of threats to Australian birds

Date:

2019-04-01

\section{Citation:}

Garnett, S. T., Butchart, S. H. M., Baker, G. B., Bayraktarov, E., Buchanan, K. L., Burbidge, A. A., Chauvenet, A. L. M., Christidis, L., Ehmke, G., Grace, M., Hoccom, D. G., Legge, S. M., Leiper, I., Lindenmayer, D. B., Loyn, R. H., Maron, M., McDonald, P., Menkhorst, P., Possingham, H. P. ,... Geyle, H. M. (2019). Metrics of progress in the understanding and management of threats to Australian birds. CONSERVATION BIOLOGY, 33 (2), pp.456-468. https://doi.org/10.1111/cobi. 13220.

Persistent Link:

http://hdl.handle.net/11343/284793 